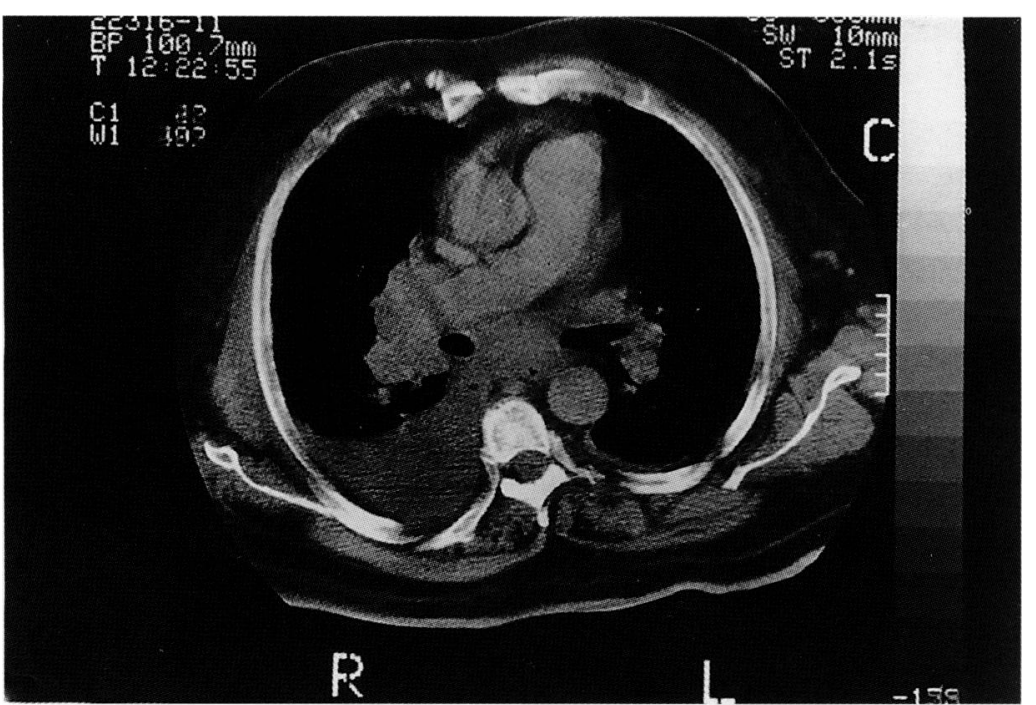

Figure 2 Contrast enhanced computed tomographic scan of the chest showing bilateral hilar adenopathy, posterior mediastinal adenopathy, and bilateral pleural effusion. only when the patient is cooperative and has no bleeding diathesis. It is usually an easy, efficient and safe procedure.

Mediastinal amyloidosis occurs infrequently and may be confused with other tumours more usually found in this region. The diagnosis should be considered in the evaluation of a large mediastinal mass. Percutaneous needle biopsy may be sufficient to provide a definitive diagnosis.

1 Jenkins NCF, Potter M. Calcified pseudotumoral mediastinal amyloidosis. Thorax 1991;46:686-7.

2 Naschitz JE, Yeshurun D, Pick AI. Intrathoracic amyloid lymphadenopathy. Respiration 1986;49:73-6.

3 Osnoss KL, Harell DD. Isolated mediastinal mass in primary amyloidosis. Chest 1980;78:786-8.

4 Wilson SR, Sanders DE, Delarue NC. Intrathoracic manifestations of amyloid disease. Radiology 1976;120:283-9. 5 Celli BR, Rubinow A, Cohen AS, et al. Patterns of pulmonary involvement in systemic amyloidosis. Chest 1978;74:543-7. 6 Franklin EC. Some unresolved problems in amyloid disease. Am f Med 1979;66:365-7.

\section{Adult congenital lobar emphysema in pregnancy}

\author{
Paul S Critchley, \\ Christopher P Forrester-Wood, \\ Paul D Ridley
}

\begin{abstract}
A young woman presented with left sided chest pain. Chest radiography revealed a hyperexpanded left upper lobe and the rare diagnosis of congenital lobar emphysema was made. She was then found to be pregnant. Thoracotomy and left upper lobectomy were performed during the pregnancy without adverse effects to the mother or fetus. The implications of pregnancy on the surgical management of this rare condition are discussed.

(Thorax 1995;50:909-910)
\end{abstract}

Department of

Thoracic Surgery,

Frenchay Hospital, Bristol BS16 1LE, UK

P S Critchley

C P Forrester-Wood P D Ridley

Reprint requests to: Dr P S Critchley.

Received 31 March 1994 Returned to authors 8 June 1994

Revised version received 26 August 1994 Accepted for publication 5 September 1994
Keywords: congenital lobar emphysema, pregnancy.

An 18 year old woman presented to her family doctor with left sided chest pain. This followed a minor coughing episode, although inhalation was denied. She had previously been fit and well. The chest radiograph revealed hyperexpansion of the left upper lobe with mediastinal shift (fig 1). Computed tomographic scanning showed an emphysematous left upper lobe (fig 2). Respiratory function tests revealed a forced expiratory volume in one second $\left(\mathrm{FEV}_{1}\right)$ of 1.71 and a forced vital capacity (FVC) of $2 \cdot 11$, both $50 \%$ of her predicted values. She was therefore referred to our thoracic unit for bronchoscopy in view of the possibility of an obstructing foreign body. At this stage she was found to be six weeks into her first pregnancy. Subsequent bronchoscopy failed to show an obstructing endobronchial lesion and diagnosis of congenital lobar emphysema was made. As the pregnancy progressed she became increasingly dyspnoeic and the chest radiograph showed further mediastinal shift.

At 26 weeks gestation a thoracotomy and left upper lobectomy were performed. The operative procedure consisted of a standard

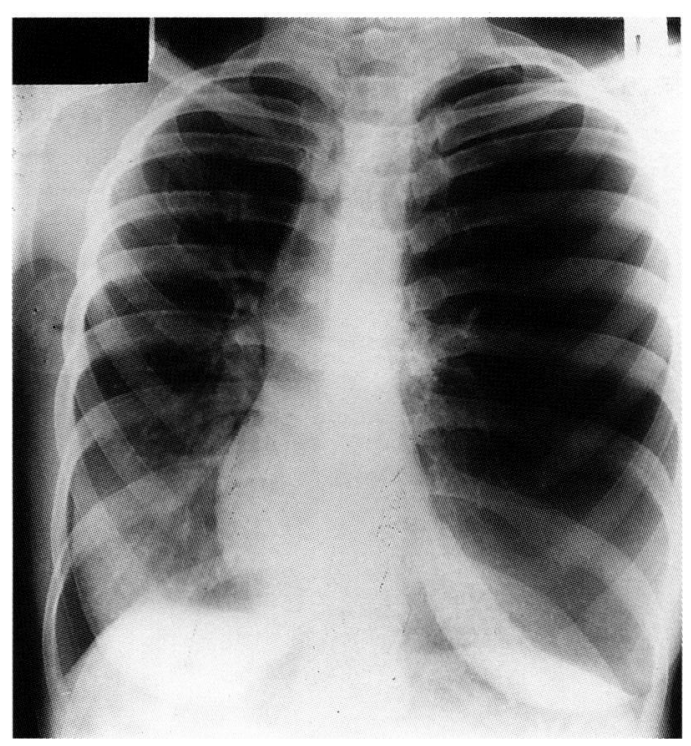

Figure 1 Chest radiograph at presentation showing hyperlucent left upper lobe with mediastinal shift toward the right. 


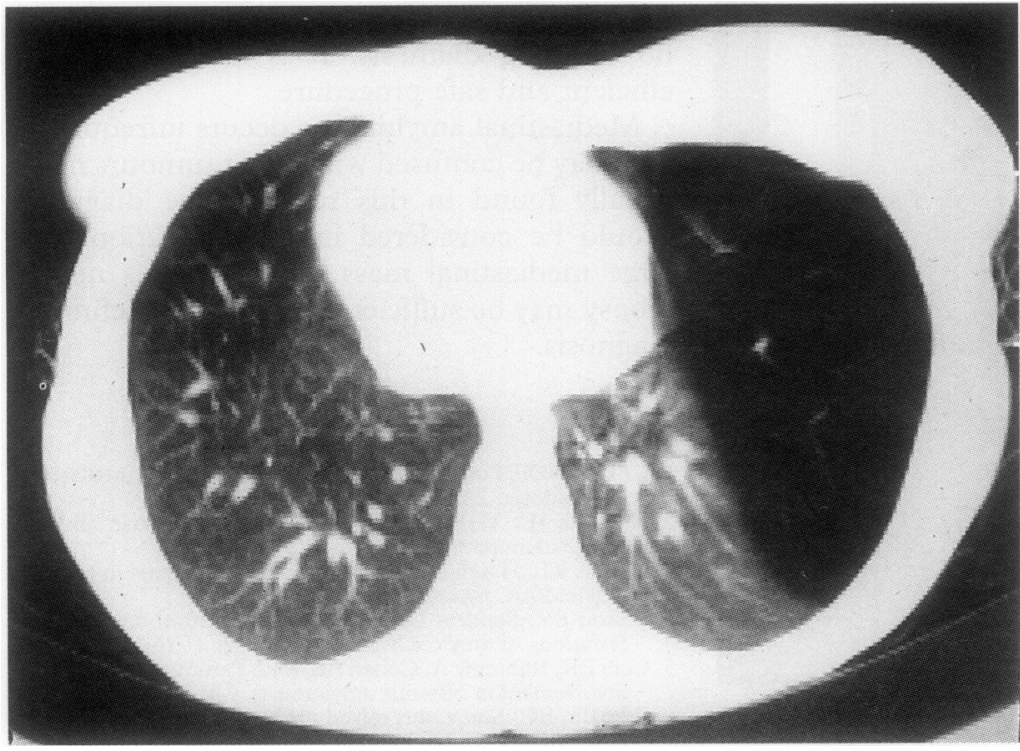

Figure 2 Computed tomographic scan of the chest showing hyperlucent left upper lobe. The mediastinum is shifted toward the right.

posterolateral approach to the left hemithorax. A grossly emphysematous upper lobe was resected; the remaining lung tissue was macroscopically normal. She made a routine postoperative recovery and 13 days later was discharged home.

Follow up at six weeks was satisfactory. The chest radiograph showed resolution of the mediastinal shift. Respiratory function tests showed an improvement in both $\mathrm{FEV}_{1}$ to 2.51 and FVC to 3.01 . The patient went on to deliver a healthy full term baby without difficulty. At one year both mother and baby were well.

Histological examination of the resected lobe showed widely distended alveolar air spaces with minimal destruction of lung tissue. This was consistent with the clinical and radiological diagnosis of congenital lobar emphysema.

\section{Discussion}

Congenital lobar emphysema is an uncommon bronchopulmonary malformation which nearly always presents in the first months of life. ${ }^{1}$ Most cases affect the left upper lobe. ${ }^{2}$ Symp- toms usually include respiratory distress and/ or recurrent pulmonary infections. ${ }^{3}$

In congenital lobar emphysema lobectomy is usually the treatment of choice. Respiratory function is expected to improve, especially when mediastinal shift has occurred. ${ }^{4}$

There are few reported cases presented in adult life. ${ }^{56}$ This case is unusual in that, upon detection, pregnancy was diagnosed, so the management decisions become more complicated because of risks to both mother and fetus.

The optimal timing of surgery is controversial. Intrapartum general anaesthesia and thoracotomy are well tolerated without excessive risk to the fetus, provided they are performed after the period during which organogenesis occurs - namely, the first trimester. ${ }^{7}$ In the third trimester there is increased cardiopulmonary demand as the fetus enlarges. The exact timing of thoracotomy should, of course, be dictated by the patient's clinical course. In this case the elected time of operation was towards the end of the second trimester when the risks to both mother and fetus were thought to be least. This coincided with the progressive dyspnoea and worsening chest radiograph.

In conclusion, the optimal time to operate on pregnant patients with congenital lobar emphysema is currently uncertain. We have presented a case of an adult undergoing left thoracotomy and pulmonary resection at 26 weeks into her pregnancy with a satisfactory outcome for both mother and fetus.

1 Haller JA Jr, Golladay ES, Pickard LR, Tepas JJ, Shorter NA, Shermeta DW. Surgical management of lung bud anomalies: lobar emphysema, bronchogenic cyst, cystic anomalies: lobar emphysema, bronchogenic cyst, cystic adenomatoid malformation and intralobar pulm. Ann Thorac Surg 1978;28:33-43.

2 Hendren HW, McKee D. Lobar emphysema of infancy. $\mathcal{f}$ Pediatr Surg 1966;1:24-39.

Murray GF. Congenital lobar emphysema (collective review). Surg Gynecol Obstet 1967;124:611-25.

4 Bailey PV, Tracy T Jr, Connors RH, deMello D, Lewis EJ, Weber TR. Congenital bronchopulmonary malformations. f Thorac Cardiovasc Surg 1990;99:597-603.

5 Wegener WA, Velchick MG. Ventilation-perfusion scintigraphy in an adult with congenital unilateral hyperlucent lung. Clin Nucl Med 1990;15:683-7.

6 McDonald CF, Pierce RJ, Barter CE, Chou ST, Daniel FJ. Congenital lobar emphysema requiring surgery in adult Congenital lobar emphysema requit

7 Terndrup TE, Bosco SF, McLean ER. Spontaneous pneumothorax complicating pregnancy: case report and review of the literature. $\mathcal{f}$ Emerg Med 1989;7:245-8. 